\title{
International employability: Stakeholder attitudes at an international university in Malaysia
}

\author{
Lucy Bailey $^{1}$ and Gudrun Ingimundardottir ${ }^{1}$ \\ lucy.bailey@nottingham.edu.my; gudruningimundar@ktj.edu.my \\ ${ }^{1}$ University of Nottingham, Malaysia Campus
}

\begin{abstract}
This paper critically examines conceptions of international employability. Drawing on a study of stakeholder views on the employability curriculum at the Malaysia campus of a British university, the paper questions whether there is an identifiable notion of international employability. Contrasting the perceptions of Malaysians and expatriates, both lecturers and students, it is suggested that employability is a blurred, evolving and culturally based concept. In questioning the existence of an identifiable notion of 'international employability', the paper suggests that universities with large numbers of overseas/ international students and staff need to give more attention to understanding competing notions of employability. Moreover, universities with nationally diverse student bodies may need to develop multiple employability curricula to meet their varied needs.
\end{abstract}

Keywords: Graduate employability, international higher education, Malaysia, employability curriculum

\section{Introduction}

Although increasing numbers of universities claim to have an international outlook or to serve a global university, the concept of an international university remains contested and complex. A university could be deemed international because of the composition of its staff and/ or student bodies. It could be deemed international because it is operating off-shore campuses or programmes. Finally - and implicit in becoming an international university in either of the previous two senses - a university's internationalism could be premised on the idea that its educational goals are in some sense global - that it offers a curriculum that can meet at once the needs of students from different countries and continents. This last form of internationalism forms the focus of this paper, and necessitates ensuring that the content knowledge, the forms of learning and the learning outcomes are universally desirable. Whilst attempts have been made in recent decades to constructively critique academic curricula that are, arguably, dominated by dead white Anglo-Saxon/ European males (Shapin, 1994; Parker, 1997), and more recently to identify the ways in which (Eastern) Confucian approaches to learning differ from (Western) Socratic approaches (Li, 2005), this paper will suggest that the discourse of employability remains rooted in the needs of developed Western nations and cultures, and that the employability curriculum needs to adapt to reflect a less culturally-limited approach. These conclusions are reached based on an analysis of conceptions of employability at an international campus of a UK university.

In the UK, the emphasis on employability at higher education institutions is a preoccupation that has grown over the past two decades (Knight \& Yorke, 2003; Boden \& Nedeva, 2010). 
Critics of this preoccupation range from those who have argued that it all too frequently attempts to address, in a module or in a semester, measures that need to be embedded across an undergraduate program (Knight \& Yorke, 2003), to those who see it as a discursive shift which is central to the neoliberalisation of higher education (Boden \& Nedeva, 2010). As HE has become increasingly internationalised over the last decade, with British universities increasingly offering degrees to those studying outside the national borders, it is pertinent to examine in more detail what an interest in an employability curriculum might mean in an international setting.

The data analysed here are from a study of stakeholder perspectives on an extra-curricular 'employability' program that is offered to students attending a British university in Malaysia; for the purposes of this paper, we shall simply term it the 'Award'. The Award is optional, and students elect whether to sign up to modules, which are entirely separate from their academic program. Students are not charged a fee for these additional modules, although the modules that are successfully completed do appear on their degree transcripts. In addition, students completing three modules are deemed to have finished the Award, and are given an additional Award certificate upon graduation. The modules cover a wide range of volunteering, work experience, mentoring, language, and career skills, with a reflective assessment component built into each module; there is a strong emphasis on so-called 'soft skills' development. For the research, staff, students and alumni of the university were interviewed in order to gain their perceptions of the Award. This paper analyses the data from these interviews to interrogate conceptions of employability in an international context, examining how a university with a claimed international outlook and under the purview of a foreign tertiary institution 'conceptualises' the notion of employability and delivers it to its students. The implications of the findings for employability and career programs in higher education are discussed.

\section{Literature Review}

Employability is a contested term (Knight \& Yorke, 2003; Rothwell, Herbert \& Rothwell, 2008; Tomlinson, 2012), with different employers, for instance, placing differing emphases on the skills required for employability. Although the call for employability in higher education is becoming ever louder, Moreau and Leathwood (2006) are critical of the increasingly dominant discourse of employability in the UK, arguing that systematic social inequalities are overlooked by the rhetoric of individual responsibility. Knight and Yorke (2003) are also highly critical of the official approach taken in the UK to measuring employability in terms of the graduate employment rate within six months of graduation, suggesting that this ignores important factors like economic cycles, regional variation and employment discrimination against certain groups. Within such a discourse, employability has shifted from being seen as an area for university discretion to an area of their performance that is increasingly scrutinized by the state (Boden \& Nedeva, 2010). Employability, therefore, does not represent a fixed attribute or set of assets; rather, employability, for most people, is for life (Yorke, 2006, p. 14), and is a discourse that reflects current political preoccupations, both at national and international level.

Traditionally, employability has been conceptualised as a skill-based concept. Following this approach, several researchers (for instance, Dacre Pool \& Sewell, 2007; Harvey, 2005; Glover, Law \& Youngman, 2002) have pointed out that there are several aspects to employability, including skills related to finding a job, finding a job at graduate level, deploying skills within that job, retaining employment and pursuing a fulfilling career. A common identifying feature of this conception of employability, however, seems to be what De Vos, De Hauw and Van der Heijden (2011) describe as:

... the continuous fulfilling, acquiring or creating of work through the optimal use of competences. These competences refer to an individual's knowledge, skills and 
abilities needed to adequately perform various tasks and carry responsibilities within a job, and their adaptability to changes in the internal and external job market (p. 439).

Furthermore, when referring to an individual's skills and knowledge, it is important to recognise that these qualifying attributes can be specific to the job at hand (for example specific technical knowledge), but can also be comprised of a range of transferable skills that do not form a dichotomy with the former but serve to complement and further enhance the specific knowledge required each time. Such skills could include analytical thinking, successful time management, self-reflection, leadership skills, and the motivation and confidence to continuously adapt to changing environments and teams of work (Glover et al., 2002). They can also include the group of skills that contribute to career management (Bridgstock, 2011), such as the ability to employ social networks effectively.

A second conceptualization of employability, however, focuses on 'talent' rather than skills. Talent is rooted in an applicant's character and their general orientation to the world, and there is a growing body of evidence to suggest that multi-national companies now tend to seek 'talent' rather than technical capabilities (Lauder, 2014; Brown, Lauder \& Sung, 2015). Employability can therefore be said to be a 'psycho-social construct' (De Vos, et al., 2011, p. 439), that is, it is made up of elements that are influenced both by the environment (job requirements or subject-specific knowledge for example) and personal psychological attributes, the exact inter-dependencies between these being context-dependent. There is a growing bank of research suggesting that employers are placing increasing emphasis on recruiting graduates who have 'work readiness' across this broad range of competences (Caballero \& Walker, 2010).

The question remains how such competences can be integrated into a university experience, and whether competences that have been honed for a European, North American or Australian job market are applicable when European, North American or Australian higher education institutions sell their degrees in other parts of the world. There is some evidence to suggest that Asian students have placed more emphasis on studying abroad as a way to differentiate themselves from other graduates in the job market, rather than on extracurricular activity, but that UK students may now be following this practice to an increasing extent (Brooks, Waters \& Pimlott-Wilson, 2011). Whilst there has been some study of students' perceptions of their employability skills (for example, Rothwell et al., 2008), the degree to which these are developed in a globalised education system remains open.

Cranmer (2006) argues that the classroom structure is ill-suited to developing the kinds of skills most valued by employers. She suggests that resources should be directed towards securing job placements or internships for students that would instead take them outside of the classroom environment to gain the knowledge and skills needed that fall outside their core curriculum. The university should, as a result, serve as an enabler for graduates (Harvey, 2005) instead of an educator in the strictest sense of the term. However, as McGrath (2009) points out, there are ways in which employability can be embedded in the curriculum - for example through projects that develop transferable skills. What is important is not solely to focus on the development of an additional skill set, but also to make sure that those skills are in accordance with demand and requirements from the job market (Harvey, 2005). This conception of employability gives universities an additional role in investigating those needs and to serve as a mediator between potential employees and employers (Zaharim et al., 2009). However, since the socio-cultural environment is a significant variable when identifying job market requirements (Rothwell \& Arnold, 2007), it draws into question whether culturally decontextualised employability skills can be identified for the 'global student'. Continued research and revisiting of market supply and demand is necessary, not the least in emerging markets such as Malaysia (Gurvinder \& Sharan, 2008), where the 
growth and development of higher education must go hand-in-hand with such socio-cultural and economic considerations.

Research carried out in Malaysia on employability of university graduates (see for example Gurvinder \& Sharan, 2008; Husain, Mokhtar, Ahmad \& Mustapha, 2010; Zaharim et al., 2009) has revealed that employers' expectations of university graduates do not differ significantly from those of their counterparts in countries such as the United Kingdom (see for example Cranmer, 2006); however, some differences have been noted. For example, an additional requirement of fluency in English (and Malay for work in government-run institutions) is included as one of the elements that make up employability of graduates (Wye \& Lim, 2009) in Malaysia. Moreover, there is evidence of a mismatch between the employability skills Malaysian students feel they have best developed at university and the importance given to these skills by local employers (Wye \& Liew, 2005). While it is important to caution against the naïve assumption that employers necessarily know best (McGrath, 2009), it is nevertheless interesting to note that Wye and Lim's (2009) study revealed that the cultivation of skills, such as the development of problem-solving skills, communication and workplace negotiation, within higher education had not met the standard required by Malaysian employers, although levels of numeracy and computer literacy were reported as being high and generally well developed at university. This is consistent with Gurvinder and Sharan's (2008) findings that Malaysian graduates were lacking in most areas related to communication and adaptability, but often highly competent in matters directly related to their degree or the subject-specific knowledge required for their particular vocation.

Students' perceptions of their skill levels provide an interesting complement to the employer perspective. Shafie and Nayan (2010) surveyed Malaysian students at a local university to identify the employability skills they believed to be most important to employers. The students identified personal attributes as the most important, followed by team work and selfmanagement. Communication skills and the ability to learn were seen as less important than these three. Shafie and Nayan (2010) elaborated on the idea of personal attributes for employment:

Personal attributes include loyalty, commitment, honesty, integrity, enthusiasm, reliability, personal presentation, common sense, positive self-esteem, a sense of humor, motivation, adaptability, a balanced attitude to work and home life and ability to deal with pressure (p. 121).

It seems, then, that the way in which employability is conceptualised by stakeholders in Malaysia is not necessarily the same as that in the UK. This is a point that has been suggested by previous researchers. Rooney et al., (2006) have identified international variations in how employability is understood even when solely considering one degree subject, geography. They note that 'employability' is a term that does not exist in some languages (e.g. Italian or Spanish), an issue that is rarely addressed in some national contexts.

Similarly, Speight, Lackovic and Cooker (2012) have identified subtle differences in the emphasis given to various aspects of employability between the stakeholders on the China Campus and the UK Campus of a UK university. They found that staff on the China Campus placed greater emphasis on both interdisciplinarity and internationalization in employability, seeing this as a way of differentiating themselves from Chinese universities. Some of the staff at the China Campus suggested that there are contrasts between Chinese and Western ways of communication and that to achieve career success, students needed to be educated about both. Speight, Lackovic and Cooker (2013) found their stakeholders argued that international employability was achieved at an international campus through exposure to staff and students from other cultural contexts. 
This paper queries this assumption by exploring the participants' perceptions of two related issues. While these were not questions directly posed to the participants, their comments implicitly revealed their assumptions regarding the issues of:

a) What is international employability?

b) What is the significance given to studying at an international campus?

\section{Research Methods}

The campus of the UK university studied for this research is a private university in Malaysia and has an internationally diverse student body; approximately 60 per cent are Malaysians, one per cent are British, and 39 per cent are from the rest of the world. Over 80 per cent of the student body is comprised of undergraduates. It should be noted that several UK universities have campuses in Malaysia, but the numbers remain small enough that any more contextualizing information about the university would serve to identify it. This study employed both focus groups and interviews as a way of exploring the views of academic staff and students at the university about their views of the extra-curricular employability program. Ethical approval was sought for the research within the university, and the practices employed followed the ethical guidelines of the British Educational Research Association.

Eight members of the academic staff were directly involved in the program at the time of the study, and all of these were interviewed for the study. In addition, twelve academics, not involved in the Award, were recruited across all faculties. These were recruited by asking the Director of Undergraduate Studies in every school either to participate or to suggest an alternative participant.

Recruiting student participants for the study proved challenging. Initially, stratified sampling of students was employed, with the aim of including graduates with the Award, graduates without the Award, undergraduates taking the Award and undergraduates not involved in the Award. An invitation to participate was sent to all graduates who had completed the Award (36 to date) as well as to a random sample of graduates who had not completed the Award. However, in the light of a low response rate from students, snowball sampling was then employed to recruit further non-Award graduates. Two focus group interviews were also conducted with current undergraduates, using purposive sampling to ensure that undergraduates engaged in the Award and those not engaged in the Award were represented, and subsequent snowball sampling was used to ensure that all faculties were represented. These efforts resulted in a total of eighteen students (including some former students) participating in the research. The following table summarises the participants in the study.

\section{Table 1: Research Participants}

\begin{tabular}{|l|c|l|l|c|}
\hline Total staff interviewed & $\mathbf{2 0}$ & Total students interviewed & $\mathbf{1 8}$ \\
\hline $\begin{array}{l}\text { Staff involved in the } \\
\text { Award }\end{array}$ & 8 & $\begin{array}{l}\text { Students involved in the } \\
\text { Award }\end{array}$ & $\begin{array}{l}\text { Undergraduates } \\
\text { Graduates }\end{array}$ & 4 \\
\hline $\begin{array}{l}\text { Staff not involved in the } \\
\text { Award }\end{array}$ & 12 & $\begin{array}{l}\text { Students not involved in } \\
\text { the Award }\end{array}$ & $\begin{array}{l}\text { Undergraduates } \\
\text { Graduates }\end{array}$ & 4 \\
\hline Faculty of Engineering & $4^{*}$ & Faculty of Engineering & 7 \\
\hline Faculty of Science & $3^{*}$ & Faculty of Science & 3 \\
\hline $\begin{array}{l}\text { Faculty of Arts and } \\
\text { Social Sciences }\end{array}$ & $5^{*}$ & Faculty of Arts and Social Sciences & 8 \\
\hline \multicolumn{3}{|l|}{ Total interviewees 38 } \\
\hline
\end{tabular}

Bailey, L. \& Ingimundardottir , G. (2015). International employability: Stakeholder attitudes at an international university in Malaysia. Journal of Teaching and Learning for Graduate Employability, 6 (1), 44-55. 
* Note: Figures only given for non-Award staff, since some of the Award staff did not have a Faculty affiliation.

The interview schedules used were adapted, with permission, from the study of the employability curriculum at a British university in China discussed above (Speight et al., 2012; Speight et al., 2013), but were adapted slightly to suit the Malaysian context. The interviews were recorded and transcribed, then coded according to Saldaña's (2012) guidelines for qualitative coding in order to establish patterns and prevalent themes.

In the following section, the paper will analyse the perceptions of employability that were expressed in the interviews, and discuss the ways in which the students and academics felt that international employability could be achieved by attendance at an international campus of a UK university.

\section{Data Analysis and Discussion}

\section{What is international employability?}

The definitions of employability given by both staff and students were largely consistent with findings from previous research, insofar as the vast majority of interviewees cited a range of transferable skills and levels of emotional intelligence as being the most important elements of employability (e.g. Glover et al., 2002; De Vos et al., 2011). The answers that diverged most from this model were those from the Faculty of Engineering, where the emphasis on subject-specific knowledge was greater than in the other faculties and, by the same token, the importance of generic skills was valued to a lesser extent than, for example, in the Faculty of Arts and Social Sciences.

\section{a) Student views}

Among the students, the most salient identifying features of employability were elements such as leadership, confidence, initiative, creativity and 'out-of-the-box thinking', which were predominantly mentioned in relation to their extra-curricular activities, which they considered had contributed most to the development of such skills or attributes. Another prevalent feature was the notion of exposure to real-life situations or hands-on experiences within their chosen field, as well as most other experiences that took them outside the classroom format and allowed them to employ skills that perhaps otherwise would neither be used nor developed. Students cited examples of group projects, presentations or the organisation of events as a part of a team as being among the most important experiences in terms of developing desirable skills for the job market. The value of a rounded university experience was raised by a majority of the interviewees, where personal attributes such as motivation, initiative and drive would play an important role in ensuring long-lasting benefits from participating in extra-curricular activities and other projects or experiences that would enhance their university education.

However, for some, being holistic was instrumental; for instance, one Malaysian graduate explained that she pursued extra-curricular activities in order to put them on her CV, and related employability to having an 'holistic look' to her CV. It is worth noting that the Malaysia campus of this UK university is a private institution, reliant on sponsoring bodies and parents paying high fees to enable students to attend. As a consequence, the emphasis placed on immediate access to employment rather than longer-term career planning by many students, may in part reflect the high opportunity cost of such a degree.

\section{b) Staff views}

This study echoes previous work in the area in suggesting that there are significant differences in the views of relevant stakeholders (Gurvinder \& Sharan, 2000; Speight et al., 
2012). Among the academic staff, an interesting dichotomy emerged between the perception of local staff members and those from abroad, where both the perception of the readiness of graduates to enter the job market and the definition of employability differed on several major points. Foreign staff for the most part agreed on soft skills and a rounded personality as being among the chief attributes of an employable graduate, whereas the definitions given by the local staff members were more focused on the attributes needed to be recruited soon after graduation. Some local staff members brought up appearance and presentation of character as being important elements of employability, while foreign staff focused on more longitudinal aspects such as lifelong learning and adaptability within the workplace. Just as Rooney et al. (2006) found international differences in how employability was seen in a single academic subject, there were clear differences between the Malaysian and nonMalaysian academics in our study.

Secondly, while foreign staff members considered their graduates to be largely ready to enter the job market and many felt that the efforts of the university to cultivate soft skills had been sufficient, the local staff members found that their students were often ill-prepared for the realities of finding a job, even for stages as early in the process as applying and interviewing for a job. Some cited examples of students not knowing how to dress for the workplace or what questions to ask in job interviews, and others stressed the importance of teaching workplace etiquette as they found that many students were lacking in matters such as professional behaviour and workplace interaction and communication. A possible explanation for this divergence in opinions and definitions may be that most of the foreign staff members came from either the Faculty of Arts and Social Sciences or the Faculty of Science, where both the modes of instruction and objectives of the degree are different from other more vocational subjects such as engineering or pharmacy.

For example, one Malaysian member of staff defined employability as whether the student can easily get a job or not. In line with the findings of Cranmer (2006), her emphasis was on the skills that students obtained outside the conventional classroom, rather than within it. She expressed her concern that many students currently lacked knowledge about professional etiquette - for example, she cited instances of students on internships reading novels at work, turning up late on the first day, failing to dress smartly, handing in Medical Certificates on their second day, and writing poor CVs:

The way you perform during training actually reflects how you will perform during the actual work, so there's a lot of these kinds of problems, which I think maybe ten years back normally wasn't a problem, but with this generation ... In fact when I meet with a lot of employers, they say that during the interview they have a lot of students asking those questions I mentioned, and they don't expect to hear from the students like: 'Do I need to work on Saturdays? Do I have the chance to travel? Go to the US for training?' This kind of thing.

For this member of staff, the feedback given from Malaysian employers was important, and she was here adopting the role that Zaharim et al. (2009) suggest for universities, in mediating the gap between employers and students. An extract from $\mathrm{K}$, another Malaysian academic who adopted a similar approach,suggests that employability is about short-term marketability:

The moment that you graduate, you should be employed pretty soon, and making yourself marketable. I mean, when people read your résumé or your $\mathrm{CV}$, they will want to hire you. That's my understanding of employability.

$\mathrm{K}$ also mentioned the importance of grooming and etiquette, but alongside that she placed an importance on intercultural awareness. 
An extract from an interview with L, a Malaysian member of staff, exemplifies again the approach that emphasises getting a job over longer-term employability skills:

You need to get employed first in order for you to remain in employment, what we need to do is just like, the basic skills, we must have them. It means that all of us, we have that foundation in order to perform a job well and after that, when you are in a job, there will probably be specific skills for your particular profession. So that is probably the time where you really need to think about what the specific skills are that you need, and then you work on it.

In this way, we can see the Malaysian staff placing more emphasis on the work readiness (Caballero \& Walker, 2010) of graduates than the non-Malaysians. This distinction between expatriates and Malaysians was not absolute, however, and there was an exception on either side. A Malaysian academic, $\mathrm{X}$, defined employability as follows:

Employability to me is soft skills that employers seek after, that employers want. It's not only that, but the kind of skills that are lifelong learning skills. Once they have these skills, they will not become obsolete.

Conversely, Z, an international academic, argued:

I think as a university we have a responsibility to ensure our graduates leave with skills that should get them into a first-round interview, and we should provide them with opportunities to practice these.

The overwhelming majority of the staff interviewees discussed employability as if it is reified, fixed, not culturally specific, placing attention on key skills (S) that are needed by all students. Only one member of staff - an expatriate academic, who had recently moved to Malaysia from being an expatriate elsewhere in Asia - suggested that the kind of skills students require might be culturally specific. $M$ argued:

Malaysians write business letters differently to Indians, to Arabs, and we can teach people how to write a British business letter but that's not necessarily what they need. So that sort of thing might happen in the future.

$\mathrm{M}$ also examined other culturally embedded aspects of employability:

In a country like Malaysia you've got different types of English, you've got one that is closer to the prestige form, and then you've got all the way down to the street English, and I think in this particular context, in Malaysia in 2013, people don't realise where they are on the scale. Middle-class academics can move up and down at will, but a lot of people don't realise that if they're for example missing the past participle when they're writing, or dropping Malay words in, which I've seen, it isn't international English, it isn't prestige English, and I don't think that some of them realise this.

He argued that the form of English needed to work in a local family firm is different than the form of English required to work in an international company. He also noted that there is cultural variation about what to include in a job application, arguing that In terms of employability, there's a risk that we're teaching, if people are not really familiar with the culture, we'll be teaching them in vain. He used the example of the portfolio of certificates attained during your childhood which in Malaysia is seen as an important part of a job application, but which would be received with bemusement by someone from the UK. Similarly, he noted that in some cultures you need to provide a photo and write your religion on your job application, while in other cultures both of these are unacceptable.

In summary, the conception of employability communicated in the majority of the staff interviews seemed to be implicitly linked to human capital theory (Becker, 1964; De Vos et al., 2011), rather than to broader conceptions of employability, education and citizenship. 
The human capital approach to employability is ostensibly neutral; that is, it sees employability as about objective skills and unrelated to culture. By contrast, the citizenship approach is necessarily related to cultural practices. The very idea that there is a notion of employability that makes sense internationally is embedded in the human capital model. There was only one member of staff who offered a contrast to this approach. Amongst other members of staff, it seemed that a single concept of employability was being posited to meet the needs of their diverse students.

\section{The significance of an international campus}

\section{a) Staff views}

In addressing the significance of study at an international campus, a clear divide opened up between the responses of the academics and the students. The academics, both Malaysians and expatriates, were interested in the way in which exposure to multi-national classes and social circles might develop skills or attributes that enabled a student to operate effectively in an international setting in the future. There was discussion as to whether this kind of intercultural sensitivity needed to be taught explicitly or implicitly, and some of the academics reported introducing it as a key theme for certain modules in the Award. For L, a Malaysian academic, giving students these kinds of opportunities was integral to the university's 'brand':

We get our undergraduate students to be the volunteers at this international education conference, so our students will get the opportunity to work with people in the industry, and because it's an international conference, they have the opportunity to meet participants from all over the world.

This approach echoes the stakeholders, Australian academics, students and employers studied by Crossman \& Clarke (2009), who concurred that international experience under study abroad schemes builds students' soft skills and abilities to operate professionally in culturally diverse contexts.

\section{b) Student views}

By contrast, for the students in our study, having an international qualification was taken as a hallmark of quality rather than linked to any international or inter-cultural skills, an emphasis that echoes the work of Brooks et al. (2012) discussed above. For instance, F, an international student from elsewhere in Asia, explained that in his national context getting a job was about the piece of paper, rather than the content of the degree: Any foreign degree holds higher value than a local degree. Not necessarily [name of university], but any foreign degree. There were also several students who placed specific emphasis on getting a British degree, which they felt gave them higher status in the job market than if they had a degree from elsewhere.

Nearly all the students interviewed intended to pursue their careers, at least initially, in their country of origin. As a consequence, the interactions they had enjoyed with people of different nationalities received little attention, while the way that an international degree was viewed acquired more significance. Several students mentioned the importance of the Award in enabling them to work with people from different faculties; none mentioned having been exposed to further nationalities than those they met in the course of their academic work. Hence, in contrast to the Malaysian graduates studied by Shafie and Nayan (2010), these students placed less emphasis on personal attributes and more on their documentation, in the form of the degree certificate itself or a well-written CV.

In summary, the extent to which the kinds of internationalism represented by international universities parallel the kinds of international settings their students are likely to encounter in 
their working lives remains unclear. Whilst academics were anxious to develop students' skills in interacting with people from other cultures, for the students the international nature of their degree was as much a signalling device as of intrinsic utility.

\section{Conclusion}

This paper raises fundamental questions about how employability can be taught in $\mathrm{HE}$ institutions operating in a globalised market, and whether a monolithic conception of employability can meet the needs of diverse student bodies. For instance, can a definition of employability be created or developed that suits most faculties and fields of study in global contexts, and would such a definition be so broad as to prevent its having any practical utility? Just as Rooney et al. (2006) found different conceptions of employability in different national settings amongst geographers, we found that academics working on a single campus but originating from diverse settings, had similar differences. With the rise of offshore campuses for Western and Southern universities, it is concerning that our findings suggest that there is little consensus on this subject amongst academics teaching in such institutions, and even less consensus between these academics and the students with whom they work. This is a small-scale study of one off-shore campus of a British university, and the number of participants was limited. Nevertheless, as increasing numbers of universities open off-shore campuses, it offers an insight into some of the challenges presented in one particular context for the development of an employability curriculum.

This paper raises further questions for research around the relationship between international higher education and international inequalities in cultural capital. How students make economic use of their extra-curricular activities at university is intrinsically linked to structural inequalities, such as gender, race and class (Stevenson \& Clegg, 2012), but the discourse of employability overlooks social inequalities (Moreau \& Leathwood, 2006). We know from previous studies that middle-class students are better at transforming educational qualifications into economic advantage than working-class students, and that their extracurricular activities lie at the heart of this as a result of their contribution to students' cultural capital (Bathmaker, Ingram \& Waller, 2013). What is less clear is whether there are international differences in how extra-curricular activities are perceived by students, and whether the advent of employability-focused features of HE, like the Award, help to reproduce international inequalities in cultural capital, or whether they transcend them. The data presented above suggest that Malaysian staff and international staff at the university studied have different perceptions of the skills lacking in students and needing to be fostered through curricular and extra-curricular engagement. However, there seems to be greater commonality between the concerns of local and international students in their preoccupation with the short-term need to get a job, and this is a concern that more closely echoes the Malaysian staff than the views expressed by expatriate academics.

From this study, it is evident that employability remains a blurred concept; it is constantly evolving and is culturally based. In the university studied, there was no clear consensus amongst academic staff regarding the skills that students would require for employability, and there was a clear divide between the views of the expatriates and the Malaysians. Moreover, the employability skills offered by an international campus are seen as important by academics, but viewed more instrumentally by their students. These findings suggest that international employability deserves greater explicit consideration amongst staff in universities that are offering programs targeting overseas students, whether in the home nation or in off-shore programs, and that the development of multiple employability pathways might best meet the needs of diverse student bodies. Without explicit consideration of these competing notions of employability, it remains a risk that these universities will replicate Western conceptions of employability without any adaptation to culturally contrasting settings. 


\section{References}

Bathmaker, A. M., Ingram, N., \& Waller, R. (2013). Higher education, social class and the mobilisation of capitals: Recognising and playing the game. British Journal of Sociology of Education, 34(5-6), 723-743 .

Becker, G. (1964). Human capital: A theoretical and empirical analysis with special reference to education. New York: Columbia University Press.

Boden, R. \& Nedeva, M. (2010). Employing discourse: Universities and graduate 'employability'. Journal of Education Policy, 25(1), 37-54.

Bridgstock, R. (2011). Skills for creative industries graduate success. Education + Training, 53(1), 9-26.

Brooks, R., Waters, J., \& Pimlott-Wilson, H. (2012). International education and the employability of UK students. British Educational Research Journal, 38(2), 281-298.

Brown, P., Lauder, H., \& Sung, J. (2015). 15 Higher education, corporate talent and the stratification of knowledge work in the global labour market. In A. van Zanten, S.J. Ball, \& B. Darchy-Koechlin (Eds), World Yearbook of Education 2015: Elites, privilege and excellence: The national and global redefinition of educational advantage, 217-230.

Caballero, C.L. \& Walker, A. (2010). Work readiness in graduate recruitment and selection: A review of current assessment methods. Journal of Teaching and Learning for Graduate Employability, 1(1), 13-25.

Cranmer, S. (2006). Enhancing graduate employability: Best intentions and mixed outcomes. Studies in Higher Education, 31(2), 169-184.

Crossman, J.E. \& Clarke, M. (2009). International experience and graduate employability: Stakeholder perceptions on the connection. Higher Education, 59(5), 599-613.

Dacre Pool, L. \& Sewell, P. (2007). The key to employability: Developing a practical model of graduate employability. Education + Training, 49(4), 277-289.

De Vos, A., De Hauw, S., Van der Heijden, B.I.J.M. (2011). Competency development and career success: The mediating role of employability. The Journal of Vocational Behavior, 79(1), 438-447.

Glover, D., Law, S., \& Youngman, A. (2002). Graduateness and employability: Student perceptions of the personal outcomes of university education. Research in PostCompulsory Education, 7(3), 293-306.

Gurvinder, K.G.S. \& Sharan K.G.S. (2008). Malaysian graduates' employability skills. UNITAR e-journal, 4(1), 15.

Harvey, L. (2005). Embedding and integrating employability. New Directions for Institutional Research, 128(1), 13-28.

Husain, M. Y., Mokhtar, S. B., Ahmad, A. A., \& Mustapha, R. (2010). Importance of employability skills from employers' perspective. Procedia-Social and Behavioral Sciences, 7, 430-438.

Knight, P. T. \& Yorke, M. (2003). Employability and good learning in higher education. Teaching in Higher Education, 8(1), 3-16.

Lauder, H. (2014). Keynote lecture at British Association of International and Comparative Education Conference, University of Bath, UK, 8-10 September 2014.

$\mathrm{Li}, \mathrm{J}$. (2005). Mind or virtue: Western and Chinese beliefs about learning. Current Directions in Psychological Science, 14(4), 190-194. 
McGrath, S. (2009). What is employability? Learning to Support Employability Project Paper 1. School of Education: University of Nottingham.

Moreau, M. P. \& Leathwood, C. (2006). Graduates' employment and the discourse of employability: A critical analysis. Journal of Education and Work, 19(4), 305-324.

Parker, D. (1997). Viewpoint: Why bother with Durkheim? Teaching sociology in the 1990s. The Sociological Review, 45(1), 122-146.

Rooney, P., Kneale, P., Gambini, B., Keiffer, A., Vandrasek, B., \& Gedye, S. (2006). Variations in international understandings of employability for geography. Journal of Geography in Higher Education, 30(1), 133-145.

Rothwell, A. \& Arnold, J. (2007). Self-perceived employability: Development and validation of a scale. Personnel Review, 36(1), 23-41.

Rothwell, A., Herbert, I., \& Rothwell, F. (2008). Self-perceived employability: Construction and initial validation of a scale for university students. Journal of Vocational Behavior, 73(1), 1-12.

Saldaña, J. (2012). The coding manual for qualitative researchers (No. 14). London: Sage Publications.

Shafie, L. A \& Nayan, S. (2010). Employability awareness among Malaysian undergraduates. International Journal of Business \& Management, 5(8), p. 119-123.

Shapin S. (1994). A social history of truth: Civility and science in seventeenth century England. Chicago: University of Chicago Press.

Speight, S., Lackovic, N., \& Cooker, L. (2012). Stakeholder attitudes towards employability in a Sino-British university. Journal of Teaching and Learning for Graduate Employability, 3 (1), 26-40.

Speight, S., Lackovic, N., \& Cooker, L. (2013). The contested curriculum: Academic learning and employability in higher education. Tertiary Education and Management, 19(2), $112-126$.

Stevenson, J. \& Clegg, S. (2012). Who cares? Gender dynamics in the valuing of extracurricular activities in higher education. Gender and Education, 24(1), 41-55.

Tomlinson, M. (2012). Graduate employability: A review of conceptual and empirical themes. Higher Education Policy, 25(4), 407-431.

Wye, C. K. \& Lim, Y. M. (2009). Perception differential between employers and undergraduates on the importance of employability skills. International Education Studies, 2(1), 95-105.

Wye, C. K. \& Liew, C. S. (2005). Undergraduates' perceptions on the importance and development of generic skills: A case study at the Faculty of Economics and Business in UKM. In Proceeding on Human Resource Development: Practices and Directions for a Developed Malaysia (pp. 200-207), Serdang: Universiti Putra Malaysia Press.

Yorke, M. (2006). Employability in higher education: What it is-what it is not. York, England: Higher Education Authority.

Zaharim, A., Md Yusoff, Y., Omar, M. Z., Mohamed, A., Muhamad, N., \& Mustapha, R. (2009, July). Engineering employability skills required by employers in Asia. Paper presented to the 6th WSEAS International Conference on ENGINEERING EDUCATION (EE'09), Rodos, Greece. 